Article

\title{
Temperature and Imbibition Influence Serianthes Seed Germination Behavior
}

\author{
Thomas E. Marler ${ }^{D}$ \\ College of Natural and Applied Sciences, University of Guam, UOG Station, Mangilao, Guam 96923, USA; \\ thomas.marler@gmail.com; Tel.: +1-671-735-2100
}

Received: 20 March 2019; Accepted: 19 April 2019; Published: 21 April 2019

\begin{abstract}
The direct role of physical dormancy in delaying germination of Serianthes grandiflora Bentham, Serianthes kanehirae Fosberg, and Serianthes nelsonii Merrill seeds has not been adequately studied, nor has the role of temperature on germination behaviors. Imbibition testing indicated seeds with scarified testa absorbed water for the duration of a $24 \mathrm{~h}$ imbibition period, but seeds with an intact testa stopped absorbing water after $1 \mathrm{~h}$. The behavior of $S$. nelsonii seeds most closely matched those of S. kanehirae, with the pattern of water absorption for S. grandiflora seeds deviating from that for the other species. Scarified seeds germinated readily, with initial germination occurring by $50 \mathrm{~h}$ for S. nelsonii and $90 \mathrm{hr}$ for the other species, and maximum germination of $80 \%$ to $90 \%$ occurring by $60 \mathrm{~h}$ for $S$. nelsonii and $100 \mathrm{~h}$ for the other species. Predicted optimum temperature based on a fitted quadratic model was $26{ }^{\circ} \mathrm{C}$ for S. nelsonii, $23{ }^{\circ} \mathrm{C}$ for S. grandiflora, and $22{ }^{\circ} \mathrm{C}$ for S. kanehirae. Seed respiration increased within $3 \mathrm{~h}$ of imbibition for scarified seeds and continued to increase in a linear pattern. The linear slope was greatest for S. nelsonii, intermediate for S. grandiflora, and least for $S$. kanehirae, but ultimate respiration was greatest for $S$. kanehirae seeds. Seed respiration was so limited for un-scarified seeds that the instrument was unable to quantify any carbon dioxide efflux. Physical dormancy in seeds of these Serianthes species is a powerful trait that spreads out the timing of seedling emergence in natural settings and controls imbibition and germination speed in managed nurseries.
\end{abstract}

Keywords: Physical dormancy; Serianthes grandiflora; Serianthes kanehirae; Serianthes nelsonii

\section{Introduction}

Serianthes nelsonii is a critically endangered legume tree species restricted to the islands of Guam and Rota [1]. The populations are not regenerating, and seedlings that emerge in situ exhibit rapid mortality [2-4]. Moreover, thousands of propagated individuals will be required to fulfill the goals of the published species recovery plan [5,6], illuminating the mandate to successfully germinate thousands of seeds in managed nurseries. The seed-to-seedling transition is of critical importance, is the initial phenological transition of a sexually-propagated plant, and the underlying requirements for this transition are some of the most important seed traits related to plant fitness [7]. Yet germination behavior of this species has been minimally studied. A greater understanding of $S$. nelsonii germination requirements may aid in understanding the limitations to recruitment in natural settings and improve methods in conservation nurseries.

Research efforts involving endangered plant species within the United States are often limited by handling permit restrictions. For these species, using congeneric species in paired research trials or as surrogates may enable the acquisition of more answers to critical research questions. Using congeneric species is a good way to increase knowledge when seeds of a closely related species are in short supply. The genus Serianthes consists of 10 species ranging from the Malay Peninsula to New Caledonia $[4,8]$. Serianthes grandiflora and S. kanehirae are the congeneric species that are geographically close to the S. nelsonii 
range, and both have been used to augment nursery research protocols for S. nelsonii [5,9]. Studies exploring the imbibition traits and the temperature-germination relationships for these species are missing.

A hard seed coat that imposes physical dormancy on seeds is common among legumes [10-12]. For these species, any attempt to understand the seed-to-seedling transition within population regeneration strategies must include the environmental and seasonal conditions that reduce or eliminate the physical dormancy. Similarly, horticultural management of a conservation nursery charged with propagating one of these species cannot be successful without basic knowledge of how to mitigate the physical dormancy of seeds.

My first objective was to determine the speed of water absorption by S. grandiflora, S. kanehirae, and S. nelsonii seeds to more fully understand the role of physical dormancy for denying imbibition. I predicted the pattern would be similar for S. kanehirae and S. nelsonii, as the proportions and shape of the seeds are similar for these two species. My second objective was to determine the influence of incubation temperature on germination behavior of the same species. I predicted the optimal temperature range would be least for $S$. nelsonii due to its highly restricted latitudinal range in comparison to the other species. My third objective was to characterize the initial seed germination dynamics of the same species immediately after imbibition by quantifying carbon dioxide efflux from seeds. The results may enable more informed conservation decisions during recovery efforts.

\section{Materials and Methods}

\subsection{Water Absorption}

The influence of an intact seed coat on water absorption in Serianthes seeds was studied in October 2014 for S. nelsonii and April 2015 for the other species. Seeds were stored in ambient conditions on Guam between collection and experimental dates. Serianthes nelsonii seeds were collected in Guam in February 2013 (Permit TE-84876A-0), S. grandiflora seeds were collected in Bohol, Philippines in March 2015, and S. kaniherae seeds were collected in Palau in March 2015.

Water imbibition was determined in scarified versus un-scarified seeds using six replications of five seeds each for S. grandiflora, S. kanehirae, and S. nelsonii seeds. Methods to mitigate physical dormancy followed protocols as previously described $[13,14]$. Scarification of the seed coat was accomplished by opening a small hole at the midpoint of the long axis of each seed by scratching on 50-grit sandpaper until cotyledon tissue could be seen beneath the testa (Figure 1a). This approach ensured avoidance of the seed location where radicle emergence occurred. Scarified and un-scarified seeds were soaked in aerated water at a constant $24^{\circ} \mathrm{C}$.

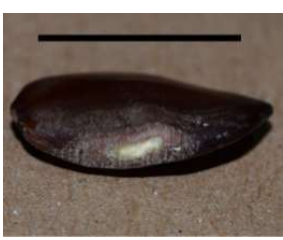

(A)

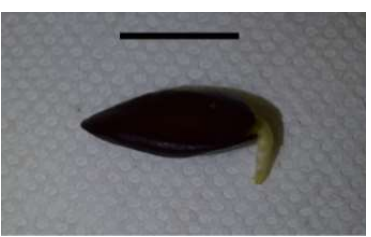

(B)

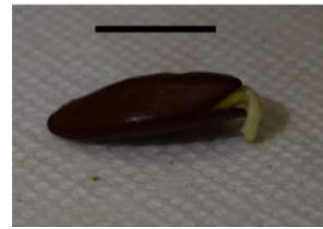

(C)

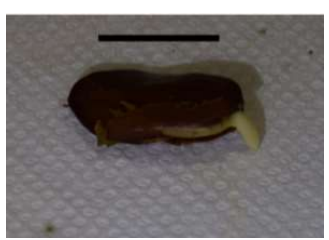

(D)

Figure 1. Appearance of Serianthes nelsonii seed after scarifying seed coat with sandpaper, exposing the light-colored cotyledon tissue (A). The general appearance of (B) Serianthes grandiflora, (C) Serianthes kanehirae, and (D) Serianthes nelsonii seeds when respiration measurements were terminated. Bars $=1 \mathrm{~cm}$.

At time $0,0.5 \mathrm{~h}, 1 \mathrm{~h}, 1.5 \mathrm{~h}$, then every hour until $24 \mathrm{~h}$, seeds were removed from the water, blotted dry on the surface, weighed, then returned to the water soak treatments. The amount of absorbed water at each time was calculated using the equation: $\% W i=((\mathrm{Wi}-\mathrm{Wf}) / \mathrm{Wf}) \times 100$, where $\mathrm{Wi}$ is fresh weight after water absorption and Wf is initial fresh weight prior to imbibition. The seeds were then germinated for use in a conservation nursery.

The results were plotted to determine the pattern in relation to time of imbibition. The response plots were characterized by linear or cubic regression patterns. The PROC GLM statement in SAS 9.3 
(SAS Institute, Cary, Indiana) was used to fit linear and cubic models to each data set. The model with the best fit was selected to define each data set.

\subsection{Temperature and Germination}

The influence of constant temperature on germination of these species was studied in October-December 2014 for S. nelsonii and June-August 2015 for the other species. Scarification of seeds was accomplished as described above. Seeds were subsequently soaked in a $10 \%$ bleach solution for $3 \mathrm{~min}$, then soaked in tap water for a total of $1 \mathrm{~h}$. Preliminary trials determined that the initial soak with bleach solution did not influence germination of seeds when compared with water only soak. The water was decanted and replaced every $15 \mathrm{~min}$ to ensure oxygenation was maintained. Each experimental unit consisted of five imbibed seeds which were sandwiched within wet paper towels and placed in $18 \times 19 \mathrm{~cm}$ plastic ziploc bags. Germination was checked every $12 \mathrm{~h}$ and the paper towels were re-moistened if needed. A seed was recorded as germinated when the radicle reached $1 \mathrm{~mm}$ in length, and was removed from the germinating bags and added to a conservation nursery. Germination for each replication continued until every seed germinated or when un-germinated seeds were unmistakably dead. Seeds of these species that do not germinate have an unambiguous appearance and odor.

Seeds were placed in darkness within germination chambers at one of six temperatures within the range of $14{ }^{\circ} \mathrm{C}$ to $39^{\circ} \mathrm{C}$. Initial germination time $\left(\mathrm{T}_{\mathrm{i}}\right)$ was the time required for the first seed within each replication to germinate. Final germination time $\left(\mathrm{T}_{100}\right)$ was the elapsed time when the last seed to germinate within each replication occurred. Six replications were used for each species and temperature regime.

The germination percentage, $\mathrm{T}_{\mathrm{i}}$, and $\mathrm{T}_{100}$ data were plotted to determine the pattern in relation to incubation temperature. All of the plots were characterized by linear or quadratic patterns. The PROC GLM statement in SAS 9.3 (SAS Institute, Cary, Indiana) was used to fit linear and quadratic models to each data set. The model with the best fit was selected to define each data set.

\subsection{Imbibition and Seed Respiration}

The influence of time since imbibition on germination behavior was studied by quantifying carbon dioxide evolution from seeds. The seed collection dates, experimental dates, and seed preparation protocols were as previously described for each species. An incubation temperature of $24^{\circ} \mathrm{C}$ was used, which was close to the optimum temperature for all three species as calculated from the temperature study described above. Following the $1 \mathrm{~h}$ imbibition period, carbon dioxide exchange was measured approximately every $3-4 \mathrm{~h}$ for the first $48 \mathrm{~h}$, then every $12 \mathrm{~h}$ thereafter until the termination of the experiment. The imbibition period was included in the initial $3 \mathrm{~h}$ period, such that the initial gas exchange measurements were $2 \mathrm{~h}$ after the seeds were removed from the water.

A CIRAS EGM-4 analyzer fitted with an SRC-1 close system chamber (PP Systems, Amesbury, MA. U.S.A.) was used to determine gas exchange. For each replication, the seeds were removed from the paper towel, carefully blotted dry, then remaining surface water was allowed to air dry to reduce condensation risk within the chamber. The five seeds were placed within a ring of modeling clay approximately $10 \mathrm{~cm}$ in diameter on a bench surface. The SRC-1 chamber was inserted into the modeling clay to form a sealed chamber of $1.171 \mathrm{~L}$ volume. The use of modeling clay to form sealed gas exchange chambers has been previously reported [15]. The EGM-4 recorded air temperature and carbon dioxide change over a $2 \mathrm{~min}$ period. This design was tested for leaks by setting up the clay ring on a portable board and inserting the chamber under ambient conditions of $405 \mathrm{ppm}$ carbon dioxide, then moving the board and chamber into a closed laboratory with elevated conditions of $950 \mathrm{ppm}$ carbon dioxide prior to initiating the 2 min recording period. The carbon dioxide within the chamber did not deviate from the initial $405 \mathrm{ppm}$ for the duration of the $2 \mathrm{~min}$ period.

Measurements on each replication were stopped when the radicle on any single seed reached $2 \mathrm{~mm}$ in length (Figure 1). The germinated seeds were then removed and added to a conservation 
nursery, and the remaining seeds were allowed to continue germination without further gas exchange measurements. The change in carbon dioxide was divided by five to place the efflux on a per seed basis. The response flux was calculated as $\mathrm{mg}$ carbon dioxide per seed per L per min. The seed respiration data were plotted to reveal a linear pattern for every replication as time elapsed following imbibition. The PROC GLM statement in SAS 9.3 was employed to fit the data with linear regression models.

A second respiration study was conducted with S. grandiflora and S. kanehirae beginning 5 December 2018. The seeds had been in storage at ambient conditions since March 2015. This study was designed to more fully understand the role of physical dormancy on seed behavior. The seed preparation and construction of replications was as described above. There were six replications per species for each of four time periods that were defined by incubation of the seeds without scarifying the testa prior to the $1 \mathrm{~h}$ soak in water. The time periods were $0,2,4$, and 6 weeks of incubation in moist paper towels prior to scarification. Every seed in the experiment was placed in the initial $1 \mathrm{~h}$ soak in water, but only the 0 weeks treatment seeds were scarified prior to the water soak. The remainder of seeds were soaked with the testa intact. For the 2, 4, or 6 weeks treatments, the six replications assigned to each time period were removed from the paper towels at the appropriate time, scarified with 50-grit sandpaper, then returned to the moist paper towels without an additional $1 \mathrm{~h}$ water soak. Respiration measurements were initiated for each treatment period with time 0 assigned to when the testa was scarified. Every replication in the un-scarified treatments was included in all of the gas exchange measurements in order to quantify seed respiration during adequate germination conditions but without testa scarification.

The responses for each species in each scarification time period were fitted with linear regression models as described above. The influence of duration of seed incubation prior to scarifying the seed testa was determined using repeated measures analysis with the PROC MIXED statement in SAS 9.3. Four response variables were subjected to the analysis: Ultimate germination percentage, the slope of the linear model, measurement temperature, and initial carbon dioxide concentration.

\section{Results}

\subsection{Water Absorption}

The un-scarified seeds of all three Serianthes species absorbed 0.5\% water during the first hour of imbibition, then ceased absorbing any more water for the duration of the $24 \mathrm{~h}$ period (data not shown). Water absorption of scarified S. kanehirae and S. nelsonii seeds increased linearly to a maximum of $55 \%$ to $60 \%$ by the end of the $24 \mathrm{~h}$ of imbibition (Figure 2). In contrast, the pattern of water absorption for S. grandiflora followed a cubic model with an ultimate absorption of about $150 \%$ water.

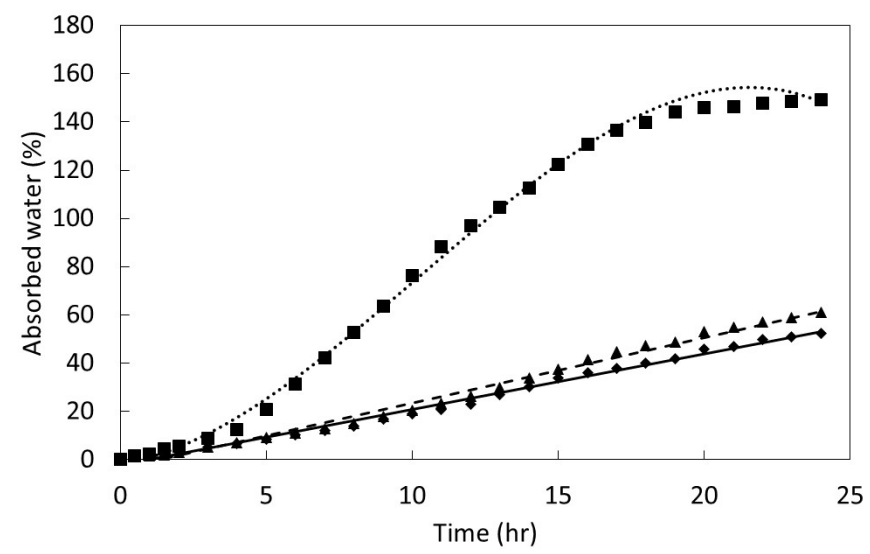

Figure 2. The influence of time in aerated water on water absorption of scarified seeds of three Serianthes species, $n=6$. Serianthes grandiflora (squares, dotted line), $y=-1.57+1.93 x+0.83 x^{2}-0.03 x^{3}, r^{2}=0.98$; Serianthes kanehirae (triangles, dashed line), $y=-3.39+2.71 x, r^{2}=0.98$; Serianthes nelsonii (diamonds, solid line), $y=-2.27+2.31 x, r^{2}=0.98$. 


\subsection{Temperature and Germination}

The influence of temperature within the range $14{ }^{\circ} \mathrm{C}$ to $39^{\circ} \mathrm{C}$ on germination percentage was defined by a quadratic model for all three species (Figure 3). The optimum temperature as defined by the fitted curve was similar among the species, with $S$. nelsonii optimum at $26{ }^{\circ} \mathrm{C}$, S. grandiflora optimum at $23^{\circ} \mathrm{C}$, and S. kanehirae optimum at $22^{\circ} \mathrm{C}$. The spread in temperature exhibiting similar maximum germination was substantial for the raw data and indicated temperatures between $21^{\circ} \mathrm{C}$ and $34{ }^{\circ} \mathrm{C}$ would be adequate for germinating all three species. The decline in germination percentage as temperature declined below optimum was greatest for S. nelsonii, intermediate for S. grandiflora, and was minimal for $S$. kanehirae. In contrast, the decline in germination percentage as temperature increased above optimum was greatest for S. grandiflora and similar for the other two species. The span of optimum temperature was least for $S$. nelsonii, as indicated by the greatest linear coefficient and greatest quadratic coefficient for the fitted models.

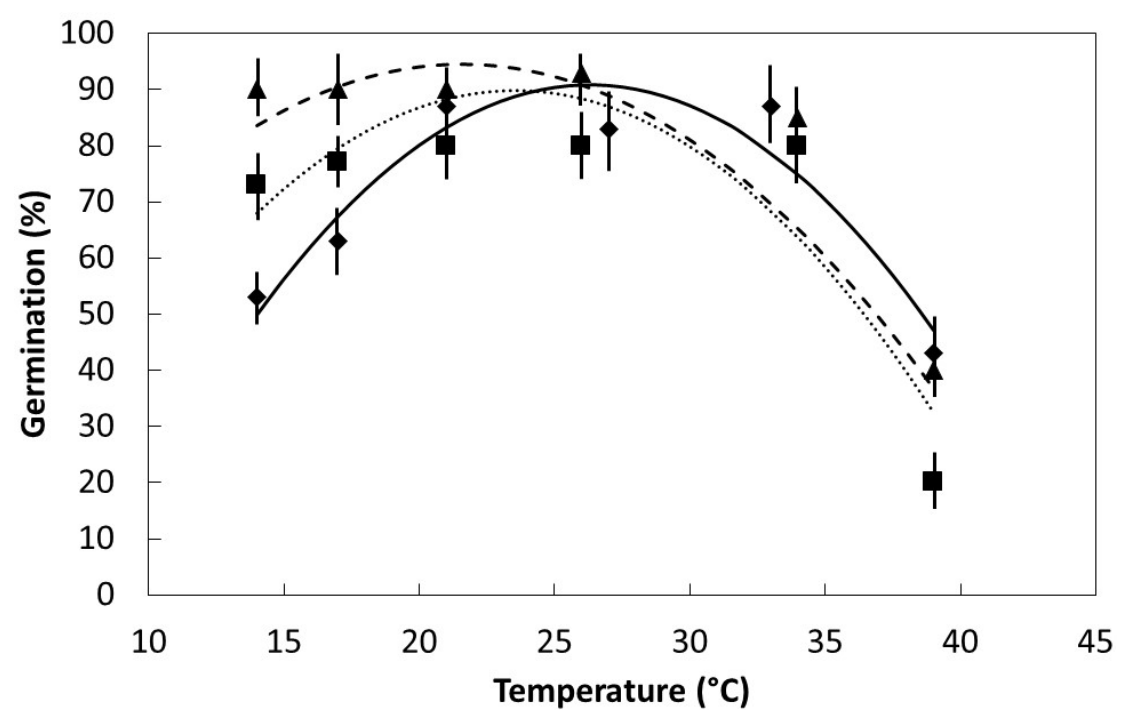

Figure 3. The influence of temperature on germination percentage for Serianthes species. Mean \pm standard error, $n=6$. Serianthes grandiflora (squares, dotted line), $y=-43.2+11.3 x-0.24 x^{2}, r^{2}=$ 0.86; Serianthes kanehirae (triangles, dashed line), $y=6.0+8.2 x-0.19 x^{2}, r^{2}=0.90$; Serianthes nelsonii (diamonds, solid line), $y=-95.9+14.2 x-0.27 x^{2}, r^{2}=0.90$.

All three species exhibited a linear decline in $\mathrm{T}_{\mathrm{i}}$ as temperature increased within the range $14{ }^{\circ} \mathrm{C}$ to $39^{\circ} \mathrm{C}$ (Figure 4). The negative slope was similar for all three species, but the intercept for $S$. nelsonii was only $62 \%$ of that for the other two species, indicating $\mathrm{T}_{\mathrm{i}}$ was least for S. nelsonii.

All three species exhibited a quadratic relationship between $\mathrm{T}_{100}$ and temperature within the range $14{ }^{\circ} \mathrm{C}$ to $39^{\circ} \mathrm{C}$ (Figure 5). The linear and quadratic coefficients of the quadratic equations were similar among the species so the shapes of the quadratic models were similar. However, as with $T_{i}$, this response variable was much less for $S$. nelsonii than for the other species. 


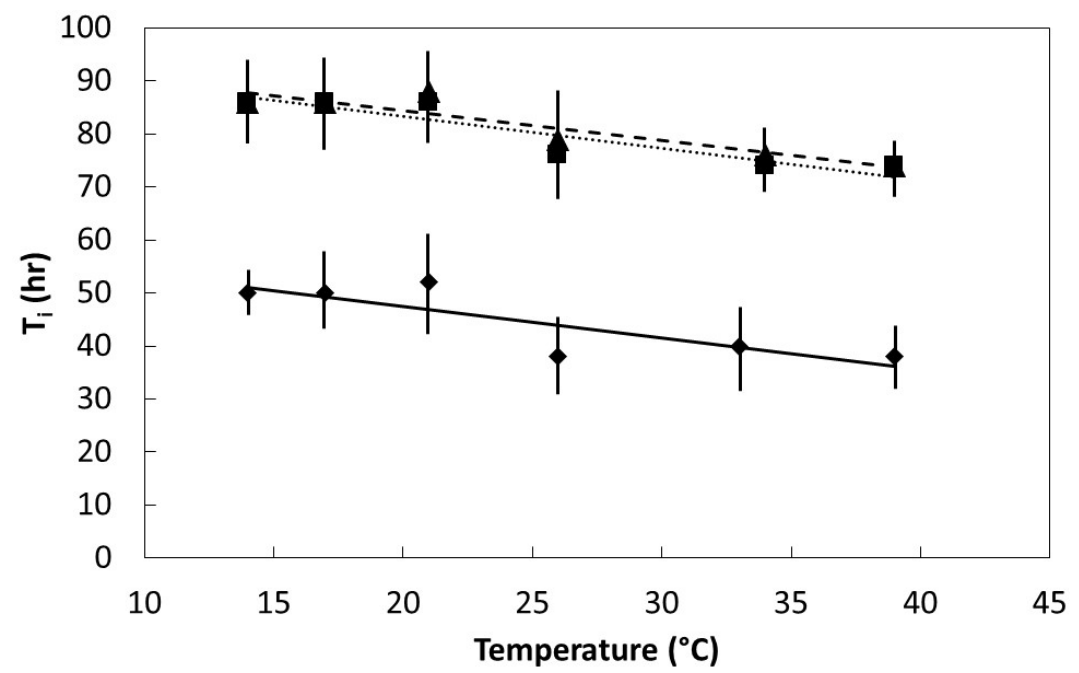

Figure 4. The influence of temperature on initial time of germination for Serianthes species. Mean \pm standard error, $n=6$. Serianthes grandiflora (squares, dotted line), $y=95.6-0.6 x, r^{2}=0.92$; Serianthes kanehirae (triangles, dashed line), $y=95.5-0.6 x, r^{2}=0.74$; Serianthes nelsonii (diamonds, solid line), $y=$ $59.5-0.6 x, r^{2}=0.74$.

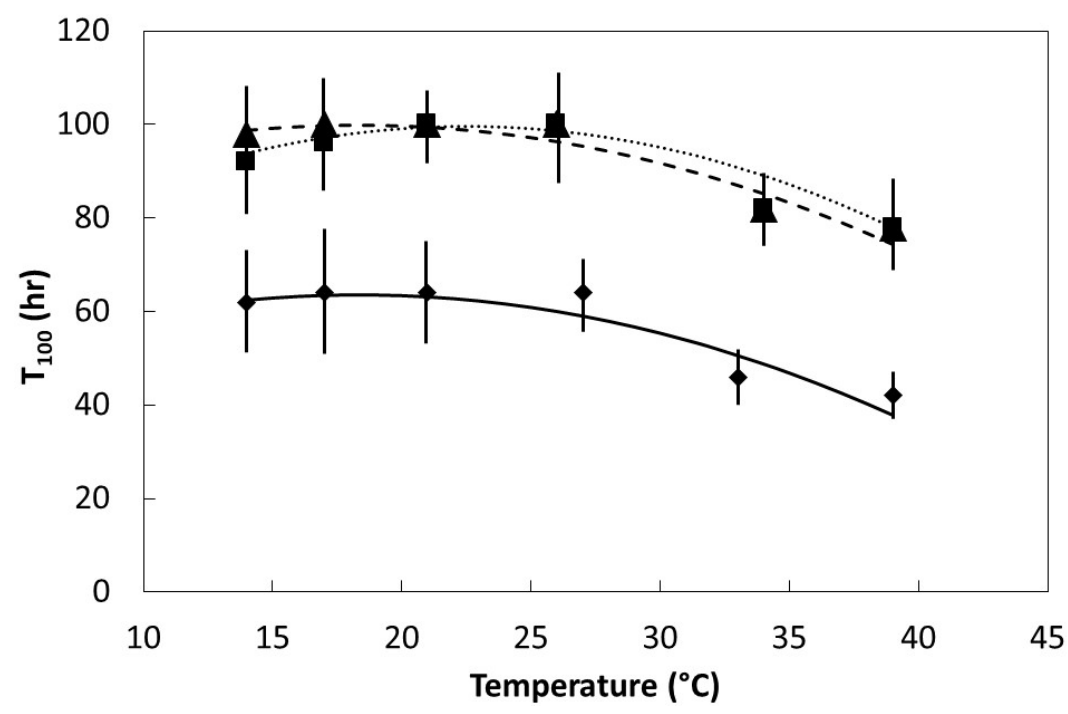

Figure 5. The influence of temperature on final time of germination for Serianthes species. Mean \pm standard error, $n=6$. Serianthes grandiflora (squares, dotted line), $y=59.2+3.6 x-0.08 x^{2}, r^{2}=$ 0.85; Serianthes kanehirae (triangles, dashed line), $y=79.8+2.2 x-0.06 x^{2}, r^{2}=0.88$; Serianthes nelsonii (diamonds, solid line), $y=43.8+2.2 x-0.06 x^{2}, r^{2}=0.88$.

\subsection{Imbibition and Seed Respiration}

An increase in seed respiration was measured within $3 \mathrm{~h}$ of imbibition for all three Serianthes species (Figure 6). The $3 \mathrm{~h}$ value of $0.45 \mathrm{mg} / \mathrm{seed} / \mathrm{min} / \mathrm{L}$ for $S$. nelsonii was more than double that of the other two species, indicating greater speed in initiating germination. Respiration increased linearly until the measurements were terminated when three seeds within each replication had germinated. This occurred after only $36 \mathrm{hr}$ for S. nelsonii, but the other two species required $72 \mathrm{~h}$ to reach this stage. The slope of the linear model was greatest for S. nelsonii, intermediate for S. grandiflora, and least for S. kanehirae. The peak respiration was similar for S. nelsonii and S. grandiflora, and these species exhibited peak respiration which was about $74 \%$ of that for $S$. kanehirae. 


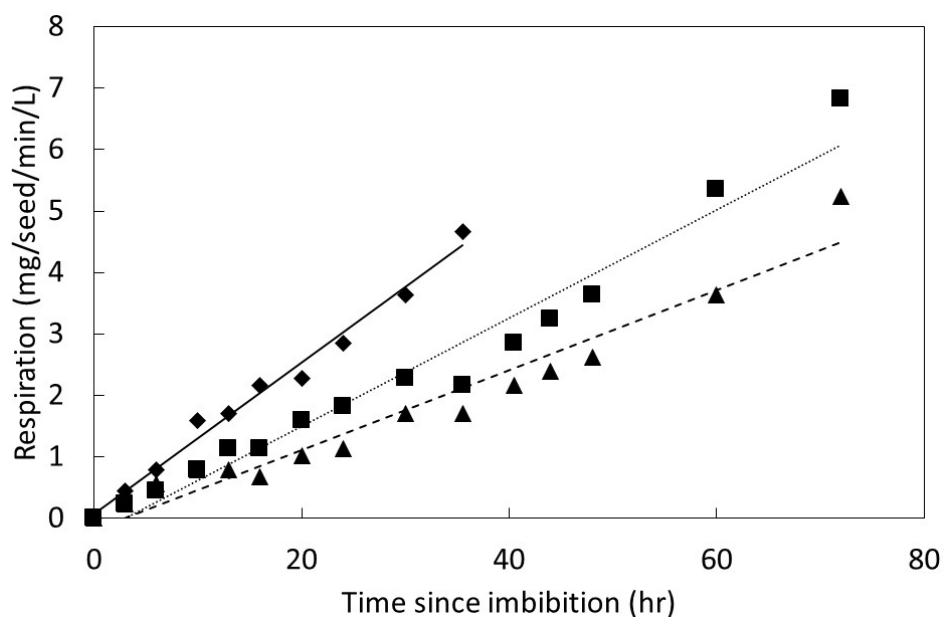

Figure 6. The influence of time since imbibition on seed respiration for Serianthes species, $n=6$. Serianthes grandiflora (squares, dotted line), $y=-0.261+0.088 x, r^{2}=0.96$; Serianthes kanehirae (triangles, dashed line), $y=-0.188+0.065 x, r^{2}=0.92$; Serianthes nelsonii (diamonds, solid line), $y=0.082+0.123 x$, $r^{2}=0.98$.

Seeds that were scarified at 0 weeks in the repeated measures study exhibited seed respiration that was similar to that in Figure 6. However, the seeds that were soaked without scarification did not emit any measured carbon dioxide during the $2 \mathrm{~min}$ gas exchange recording period. Seeds incubated in germination conditions prior to scarifying the seed coat for 2, 4, or 6 weeks exhibited increased respiration that was similar in speed and quantity to the 0 weeks treatment immediately after each treatment received the prescribed scarification. The 4 and 6 weeks replications again did not emit any measured carbon dioxide when the 2 weeks scarification treatment measurements were conducted. Similarly, the 6 weeks seeds did not emit any measured carbon dioxide when the 4 weeks scarification treatment measurements were conducted.

The germination percentage for the seeds among the four incubation treatments were not different for S. grandiflora or S. kanehirae (Table 1). Similarly, the positive linear slope that characterized the increase in seed respiration following scarification did not differ among the four incubation treatments for either species. The mean germination and mean respiration slope were similar to those in Figure 2 (at the same incubation temperature) and Figure 6. These results indicated that incubating in adequate conditions for germination for up to 6 weeks without scarifying the testa did not reduce germination performance immediately after imposing the scarification treatment. Experimental temperature and carbon dioxide concentration did not differ among the four incubation treatments.

Table 1. Parameters from repeated measures analysis comparing the manner in which Serianthes germination percentage and slope of the linear increase in seed respiration were influenced by pre-scarification incubation times. Seeds were incubated in wet paper towels for $0,2,4$, or 6 weeks prior to scarifying the seed coat to enable imbibition, $n=6$.

\begin{tabular}{cccc}
\hline Response Variable & $\boldsymbol{F}$-value & $p$-value & Mean \\
\hline S. grandiflora germination $(\%)$ & 0.5879 & 0.6323 & 82.7 \\
S. grandiflora linear slope & 0.2397 & 0.8673 & 0.088 \\
S. grandiflora temperature $\left({ }^{\circ} \mathrm{C}\right)$ & 0.1402 & 0.9344 & 28.9 \\
S. grandiflora $\mathrm{CO}_{2}(\mathrm{ppm})$ & 1.0121 & 0.4148 & 408 \\
S. kanehirae germination $(\%)$ & 1.2505 & 0.3266 & 89.4 \\
S. kanehirae linear slope & 0.7101 & 0.5609 & 0.066 \\
S. kanehirae temperature $\left({ }^{\circ} \mathrm{C}\right)$ & 0.2308 & 0.8735 & 28.6 \\
S. kanehirae $\mathrm{CO}_{2}(\mathrm{ppm})$ & 0.1897 & 0.9017 & 405 \\
\hline
\end{tabular}




\section{Discussion}

The requirements for successful seed germination and early seedling growth are rarely known for native tree species that are not important in silviculture [16]. This limitation in knowledge is amplified for species that are threatened before any empirical research has been conducted. I have begun to address these issues for Guam's S. nelsonii, a native tree that has been reduced to a single mature individual. Seed viability does not appear to be a limitation that explains the acute regeneration failures of S. nelsonii. An intact testa allows seeds of this species and the congeneric S. grandiflora and S. kanehirae to be stored long term by way of physical dormancy, even in germination-appropriate conditions. Ample seedling emergence occurs in situ [3], and extremely rapid metabolic activity and germination of scarified seeds following imbibition has been demonstrated herein. Following a break in the testa, an increase in metabolic activity of the seeds as evinced by seed respiration can be measured in only $3 \mathrm{~h}$ of water absorption. These respiration results evince the rapid initiation of $S$. nelsonii germination processes, such as mobilization of storage components and activation of DNA, cell membranes, and organelles [17]. The fairly flat $S$. nelsonii germination response within the temperature range $21^{\circ} \mathrm{C}$ to $33{ }^{\circ} \mathrm{C}$ (Figure 3) indicates the use of ambient laboratory or nursery settings or air-conditioned laboratory settings would be appropriate for germinating $S$. nelsonii seeds. The increased container substrate temperatures that result from high light conditions [13] mandate the use of darkness or deep shade for germination.

My prediction that the range in optimum temperature for germination would be least for S. nelsonii due to its restricted endemic range was confirmed. The span between the two island groups that comprise the $S$. nelsonii endemic range is $60 \mathrm{~km}$. The span between the two island groups that comprise the $S$. kanehirae endemic range is $420 \mathrm{~km}$. The indigenous range of Serianthes grandiflora is extensive, encompassing much of Malesia and beyond [18]. The decline in germination within the supra-optimal temperature range was similar among the species, but the decline in germination within the suboptimal temperature range was greatest for S. nelsonii. The inhibition of seedling emergence in full sun conditions [13], is now known to be partly due to increased temperatures of the germination medium (up to $44^{\circ} \mathrm{C}$ ), as temperatures of less than $40^{\circ} \mathrm{C}$ reduced germination in the present study. My prediction that water absorption patterns would be similar for S. kanehirae and S. nelsonii was also confirmed. Serianthes nelsonii seeds are much smaller than S. kanehirae seeds, but the length, width, and depth of these seeds exhibit similar proportions (S. kanehirae: $18.3 \times 9.6 \times 3.0 \mathrm{~mm}$; S. nelsonii: $13.0 \times 7.5 \times 2.1 \mathrm{~mm})$. In contrast, $S$. grandiflora seeds exhibit much greater depth in relation to length and width $(17.8 \times 6.8 \times 4.3 \mathrm{~mm})$, with cotyledon tissue volume being much greater relative to the seed dimensions. The depth of S. kanehirae and S. nelsonii seeds is $16 \%$ of seed length, but the depth of S. grandiflora seeds is $24 \%$ of seed length. This contrasting seed shape may explain the highly disparate water absorption curve for $S$. grandiflora in comparison to the other two species. Another notable outcome of this study was the speed of germination for $S$. nelsonii was strikingly faster than for the other species.

Physical dormancy of seeds is common in the Fabaceae family, and some of the natural factors that break down the testa to enable germination are high temperature, fluctuating temperature, and passage through the digestive tracts of animals [11,12]. Thick-walled palisade cells in the testa appear to be a common means by which imbibition of water is denied. The genus Serianthes is a member of the Mimosoideae subfamily of Fabaceae. In this subfamily, breaking physical dormancy may also involve a specialized lens [12] or a pleurogram [19] in the testa, both of which may aid initial water absorption. Although the seed coat traits such as lens and pleurogram of other Serianthes species have been observed [20], the presence or absence of such features have not been determined for the Serianthes taxa in the present study. Continued non-destructive studies are needed to determine the characteristics of all specialized structures in the $S$. nelsonii seed coat and if a minimal scarification of the outer palisade layer rather than scarification of the entire seed coat is sufficient to enable imbibition. Moreover, the use of wet paper towels or filter paper for the imbibition phase rather than full immersion may prove to be adequate. 
Seed germination is a complex process that begins as a physical phase during which water is absorbed, then transitions into a metabolic phase where myriad factors combine to eventually lead to radicle protrusion [21,22]. The metabolic phase is still not fully understood, and includes feedback loops and regulatory features such as transcription and epigenetic components that are under hormonal control [23-27]. The speed of imbibition during the physical phase, as shown in Figure 2, may not necessarily correlate directly with the speed of ultimate germination as in Figures 4 and 5, or a direct measure of metabolism as in Figure 6.

Conservation efforts with threatened terrestrial plant species often include germination of seeds to produce plants for recovery purposes and to test viability during long-term seed storage. In order to increase the understanding of germination biology of a threatened model species, these propagation steps can be designed such that non-destructive experiments enable the generation of new information in the process [28]. In this case study, all of the seedlings resulting from germinated S. nelsonii seeds were not influenced by the treatments and were added to a conservation nursery to advance recovery efforts.

These results combine with earlier publications $[2-4,13,14]$ and observations to contribute toward an understanding of the reasons for natural regeneration limitations. Physical dormancy in seeds of these S. nelsonii spreads out the timing of seedling emergence in natural settings and controls germination speed in managed nurseries. Light is not required for germination, and full sun conditions reduce germination. Numerous seedlings emerge beneath mature $S$. nelsonii trees almost every month of the year. However, these seedlings exhibit rapid mortality. In the present study, S. nelsonii was shown to exhibit much more rapid germination behaviors than the other Serianthes species. This was evident not only in the germination speed, but also in the greater initial seed respiration for S. nelsonii. Continued research efforts should focus on the limitations to successful seedling-to-sapling transition (e.g., [29]), as the seed-to-seedling transition does not appear to be a limitation.

\section{Conclusions}

The Recovery Plan for Serianthes nelsonii [6] included the critical need for more research to improve management of the species. The results herein contributed directly to that need, and the direct role of physical dormancy in delaying germination of S. nelsonii and two other Serianthes species has been demonstrated. Intact seed coats denied water absorption under imbibition conditions that enabled $50 \%$ to $150 \%$ water absorption for scarified seeds. Seed respiration increased within $3 \mathrm{~h}$ of imbibition for scarified seeds, evincing a rapid increase in metabolic activity upon imbibition. Scarified S. nelsonii seeds initiated germination by $50 \mathrm{~h}$, and the other species did so by $90 \mathrm{~h}$. Optimum germination temperatures and declines in germination within supra-optimum temperatures were similar among the species, but declines in germination within suboptimum temperatures were greatest for S. nelsonii. Physical dormancy in seeds of these Serianthes species is a powerful trait that spreads out the timing of seedling emergence in natural settings and controls imbibition and germination speed in managed nurseries.

Funding: This research received no external funding.

Acknowledgments: No take or collection was directly associated with this study. Nursery support was provided by Nirmala Dongol and Cameron Musser.

Conflicts of Interest: The author declares no conflict of interest.

\section{References}

1. Wiles, G.; Williams, E. Serianthes nelsonii. The IUCN Red List of Threatened Species 2017; Red List: Cambridge, UK, 2017. e.T30437A98715973. Available online: http://dx.doi.org/10.2305/IUCN.UK.2017-3. RLTS.T30437A98715973.en (accessed on 19 April 2019).

2. Marler, T.; Musser, C. Potential stressors leading to seedling mortality in the endemic Hayun Lagu tree (Serianthes nelsonii Merr.) in the island of Guam. Trop. Conserv. Sci. 2015, 8, 738-744. [CrossRef] 
3. Marler, T.E.; Cascasan, A.N. Number of emerged seedlings and seedling longevity of the non-recruiting, Critically Endangered Hayan Lagu tree Serianthes nelsonii Merr. (Fabales: Leguminosae) are influenced by month of emergence. J. Threat. Taxa 2015, 7, 8221-8225. [CrossRef]

4. Wiles, G.J.; Schreiner, I.H.; Nafus, D.; Jurgensen, L.K.; Manglona, J.C. The status, biology, and conservation of Seranthes nelsonii (Fabaceae), an endangered Micronesian tree. Biol. Conserv. 1996, 76, 229-239. [CrossRef]

5. Marler, T.E. Asexual reproduction to propel recovery efforts of the critically endangered Håyun Lågu tree (Serianthes nelsonii Merr.). Trop. Conserv. Sci. 2017, 10, 1-9. [CrossRef]

6. United States Fish \& Wildlife Services. Recovery Plan for Serianthes nelsonii; United States Fish \& Wildlife Services: Portland, Oregon, 1994. Available online: http://ecos.fws.gov (accessed on 21 April 2019).

7. Harper, J.L. Population Biology of Plants; Academic Press: London, UK, 1977; ISBN 0-12-325850-2.

8. Fosberg, F.R. The vegetation of Micronesia. Bull. Amer. Mus. Nat. Hist. 1960, 119, 1-75.

9. Marler, T.E. Diel root extension patterns of three Serianthes species are modulated by plant size. Plant Signal. Behav. 2017, 12, e1327496. [CrossRef] [PubMed]

10. Rolston, M.P. Water impermeable seed dormancy. Bot. Rev. 1978, 44, 365-396.

11. Baskin, C.C.; Baskin, J.M. Seeds: Ecology, Biogeography, and Evolution of Dormancy and Germination; Academic Press: San Diego, CA, USA, 1998; ISBN 0-12-080260.

12. Baskin, J.M.; Baskin, C.C.; Li, X. Taxonomy, anatomy and evolution of physical dormancy in seeds. Plant Species Biol. 2000, 15, 139-152. [CrossRef]

13. Marler, T.E.; Cascasan, A.; Lawrence, J.H. Threatened native trees in Guam: Short-term seed storage and shade conditions influence emergence and growth of seedlings. HortScience 2015, 50, 1049-1054. [CrossRef]

14. Marler, T.E. Serianthes nelsonii seed germination and seedling behavior are minimally influenced by chemical and light treatment. Horticulturae 2019, 5, 31. [CrossRef]

15. Ávila-Lovera, E.; Tezara, W. Water-use efficiency is higher in green stems than in leaves of tropical tree species. Trees 2018, 32, 1547-1558. [CrossRef]

16. Lamb, D. Forest restoration-The third big silvicultural challenge. J. Trop. For. Sci. 2012, 24, 295-299.

17. Bray, C.M. Biochemical processes during osmopriming of seeds. Water relations in seed germination. In Seed Development and Germination; Kigel, J., Ed.; Marcel Dekker: New York, NY, USA, 1995; pp. 767-789.

18. Nielsen, I.C. Mimosaceae (Leguminosae - Mimosoideae). Flora Malesiana. Series 1. 1992. Available online: www.biodiversitylibrary.org (accessed on 21 April 2019).

19. Rodrigues-Junior, A.G.; Caroline, A.; Mello, M.P.; Baskin, C.C.; Baskin, J.M.; Oliveira, D.M.T.; Garcia, Q.S. A function for the pleurogram in physically dormant seeds. Ann. Bot. 2018, mcy222. [CrossRef]

20. Gunn, C.R. Fruits and seeds of genera in the subfamily Mimosoideae (Fabaceae). Technical Bulletin No. 1681. Available online: https://ageconsearch.umn.edu/record/157649/files/tb1681.pdf (accessed on 21 April 2019).

21. Nonogaki, H.; Bassel, G.W.; Bewley, J.D. Germination-Still a mystery. Plant Sci. 2010, 179, 574-581. [CrossRef]

22. Tuan, P.A.; Sun, M.; Nguyen, T.-N.; Park, S.; Ayele, B.T. Molecular mechanisms of seed germination. In Sprouted Grains-Nutritional Value, Production and Applications; Feng, H., Nemzer, B., DeVries, W., Eds.; Elsevier Inc.: Linn, MO, USA, 2019; pp. 1-24.

23. Woloszynska, M.; Gagliardi, O.; Vandenbussche, F.; Van Lijsebettens, M. Elongator promotes germination and early post-germination growth. Plant Signal. Behav. 2017. [CrossRef]

24. Lepiniec, L.; Devic, M.; Roscoe, T.; Bouyer, D.; Zhou, D.-X.; Boulard, C.; Baud, S.; Dubreucq, B. Molecular and epigenetic regulations and functions of the LAFL transcriptional regulators that control seed development. Sex. Plant Reprod. 2018, 31, 291-307. [CrossRef] [PubMed]

25. Xu, F.; Kuo, T.; Rosli, Y.; Liu, M.-S.; Wu, L.; Chen, L.-F.O.; Fletcher, J.C.; Sung, Z.R.; Pu, L. Trithorax group proteins act together with a polycomb group protein to maintain chromatin integrity for epigenetic silencing during seed germination in Arabidopsis. Mol. Plant 2018, 11, 659-677. [CrossRef] [PubMed]

26. Jo, L.; Pelletier, J.M.; Harada, J.J. Central role of the LEAFY COTYLEDON1 transcription factor in seed development. J. Integr. Plant Biol. 2019. [CrossRef]

27. Saatkamp, A.; Cochrane, A.; Commander, L.; Guja, L.K.; Jimenez-Alfaro, B.; Larson, J.; Nicotra, A.; Poschlod, P.; Silveira, F.A.; Cross, A.T.; et al. A research agenda for seed-trait functional ecology. New Phytol. 2019, 221, 1764-1775. [CrossRef] 
28. Clemente, A.S.; Müller, J.V.; Almeida, E.; Costa, C.A.; Dias, S.L.; Brehm, J.M.; Rebelo, R.; Martins-Loução, M.A. What can routine germination tests in seed banks tell us about the germination ecology of endemic and protected species? Botany 2017, 95, 673-684. [CrossRef]

29. Marler, T.E. Thigmomorphogenesis and biomechanical responses of shade-grown Serianthes nelsonii plants to stem flexure. Plant Signal. Behav. 2019. [CrossRef] [PubMed]

(C) 2019 by the author. Licensee MDPI, Basel, Switzerland. This article is an open access article distributed under the terms and conditions of the Creative Commons Attribution (CC BY) license (http://creativecommons.org/licenses/by/4.0/). 